ROCZNIKI HUMANISTYCZNE

Tom LXVII, zeszyt $10-2019$

DOI: http://dx.doi.org/10.18290/rh.2019.67.10-9

JOANNA OLECHNO-WASILUK

\title{
POPULARYZACJA JĘZYKA I KULTURY ROSYJSKIEJ WŚRÓD DZIECI. FENOMEN SERIALU ANIMOWANEGO MASZA I NIEDŹWIEDŹ
}

Najlepszą motywacją w edukacji dzieci jest zabawa - naturalny element ich świata. Uwzględnia to m.in. podstawa programowa wychowania przedszkolnego, dotycząca przygotowania dzieci do posługiwania się językiem innym niż ojczysty, która podkreśla potrzebę zapewnienia dzieciom możliwości: osłuchania się z językiem obcym poprzez przebywanie w środowisku, w którym jest on używany, rozwijanie wrażliwości na system dźwięków występujący w języku nieojczystym oraz ćwiczenia swojego aparatu mowy, bawiąc się dźwiękami, intonacją i rytmem języka obcego; kształtowania zainteresowania i pozytywnego nastawienia do języka obcego ${ }^{1}$.

Niezależnie od etapu nauczania języka, obiektywnym źródłem funkcjonowania motywacji uczących się jest dobór materiałów dydaktycznych, ich atrakcyjność z punktu widzenia formy i treści oraz ich wartość poznawcza i estetyczna. Wartościowym materiałem okazuje się być w tym kontekście bajka multimedialna.

Artykuł niniejszy poświęcony jest popularyzacji języka i kultury rosyjskiej wśród dzieci poprzez serial animowany Masza i Niedźwiedź. Publikacja oparta jest na doświadczeniach autorki z realizacji własnego projektu: „Понять Машу. Весело, красиво, интересно об языке и русской культуре”2 („Zrozumieć Maszę. Wesoło, kolorowo i ciekawie o języku i kulturze Rosji”, dalej „Zrozumieć

Mgr Joanna Olechno-Wasiluk - asystent w Instytucie Słowiańszczyzny Wschodniej Uniwersytetu Warmińsko-Mazurskiego w Olsztynie; e-mail: joanna.olechno-wasiluk@uwm.edu.pl

${ }^{1}$ Rozporządzenie Ministra Edukacji Narodowej zmieniające rozporządzenie w sprawie podstawy programowej wychowania przedszkolnego oraz kształcenia ogólnego w poszczególnych typach szkół (podpisane w dniu 30 maja 2014 r.) dostęp online https://www.gov.pl/web/edukacja (dostęp: 15.12.2018).

${ }^{2}$ Więcej w artykule: J. OLEChNo-WASILUK, Из опыта приобщения к русскому языку и культуре польских дошкольников, „Вестник ТГПУ” 2016, nr 3, s. 93-96. 
Maszę"), który zakłada promowanie języka i kultury rosyjskiej wśród dzieci oraz przygotowanie ich do uczestnictwa w dialogu międzykulturowym.

Masza i Niedźwiedź (ros. Маша и Медведь) to animacja od lat ciesząca się niesłabnącą popularnością wśród dzieci na całym świecie. Bajkę oglądać można w kilkunastu wersjach językowych, m.in. polskiej, angielskiej, serbskiej, czeskiej, włoskiej, francuskiej, hiszpańskiej, portugalskiej, niemieckiej, fińskiej. Na polskim ekranie serial pojawił się po raz pierwszy w roku 2014. Co ciekawe, bajka w oryginalnej wersji językowej, m.in. na YouTube, oglądana jest równie chętnie ${ }^{3}$. Wysoka oglądalność oraz powodzenie serialu animowanego Masza i Niedźwiedź, szczególnie wśród dzieci, daje nauczycielom języka rosyjskiego wiele możliwości wykorzystania go w propagowaniu języka oraz kultury naszego wschodniego sąsiada.

Bajka ta stała się inspiracją dla projektu autorki niniejszego artykułu. Program „Zrozumieć Maszę” realizowany jest od roku 2016 w Instytucie Słowiańszczyzny Wschodniej Uniwersytetu Warmińsko-Mazurskiego w Olsztynie. Jest to cykl spotkań, w formie warsztatów, dla dzieci w wieku przedszkolnym. Głównym celem projektu jest popularyzacja języka i kultury rosyjskiej. Spotkania odbywają się najczęściej przy okazji imprez promocyjnych na wydziale humanistycznym bądź na prośbę konkretnych przedszkoli. W 2016 r. projekt zdobył pierwszą nagrodę w kategorii „materiały dydaktyczne” w konkursie dla nauczycieli i wykładowców języka rosyjskiego jako obcego organizowanym przez Państwowy Uniwersytet Pedagogiczny w Tomsku oraz Instytut Polsko-Rosyjski we Wrocławiu ${ }^{4}$.

Wybór serialu Masza i Niedźwiedź na motyw przewodni spotkań z dziećmi nie jest przypadkowy. Animacja ta jest skarbnicą elementów kultury rosyjskiej przekazywanych małym widzom ,przy okazji” narracji. Bajka zawiera też wiele stereotypów na temat Rosji i Rosjan. Jednak, jak podkreślają językoznawcy, stereotyp jest „koniecznym elementem wspólnego języka i kodu kultury”. Warto podkreślić, że stereotypizacja obejmuje wszystko, co człowiek poznaje i oswaja na swój użytek, konstruując sobie pewien model świata i scenariusze swojego w nim zachowania. Stereotypy, jak słusznie zauważa Jerzy Bartmiński, wchodzą w skład językowo-kulturowego obrazu świata danej wspólnoty komunikatywnej ${ }^{6}$.

\footnotetext{
${ }^{3}$ Według informacji podanych przez Polskieradio.pl jeden z odcinków Maszy i Niedźwiedzia obejrzało ponad 1 mld 15 milionów internautów, dostęp online https://www.polskieradio.pl/5/3/ Artykul/1560483, Rosyjska-kreskowka-Masza-i-niedzwiedz-pobila-rekord-na-YouTube (dostęp: 11.10.2018).

${ }^{4}$ Więcej o konkursie https://ip-r.org/konkurs/.

${ }^{5}$ A. KĘPIŃsKi, Lach i Moskal. Z dziejów stereotypu, Warszawa-Kraków 1990, s. 12.

${ }^{6}$ J. BARTMIŃSKI, Stereotypy mieszkaja w języku. Studia etnolingwistyczne, Lublin: Wydawnictwo UMCS 2007, s. 86.
} 
Nie należy więc zapominać o treściach poznawczych stereotypów, które dotyczyć mogą m.in. kuchni, elementów stroju, przedmiotów kojarzonych z poszczególną narodowością. Jedną z podstawowych właściwości stereotypów jest ich różnorodność i to, że mogą funkcjonować we wszystkich sferach życia. Animacja Masza i Niedźwiedź jest przepełniona stereotypami o treściach poznawczych i utrwalających. W bajce odzwierciedlony jest zwykły dzień Rosjanina, jego zainteresowania, formy spędzania czasu wolnego, ważne święta i tradycje, elementy stroju ludowego i rekwizyty kojarzące się z rosyjskością.

Problem relacji między nauką języka obcego a stereotypami jest tematem wielu publikacji w glottodydaktyce, psychologii czy pedagogice ${ }^{7}$.

Już w pierwszym odcinku bajki - Pierwsze spotkanie (ros. Первая встреча), zostały ulokowane stereotypy dotyczące Rosji i Rosjan. Poznajemy Niedźwiedzia (niedźwiedź jest symbolem Rosji; wielu cudzoziemców uważa, że zwierzę to spotkać można na ulicach rosyjskich miast), który mieszka gdzieś pod Uralem, niedaleko stacji kolejowej na trasie Moskwa-Pekin, gdzie wiedzie spokojne życie. Miś jest zasłużonym emerytowanym pracownikiem cyrku. W domu ma wiele odznaczeń i dyplomów (w przekonaniu obcokrajowców Rosjanie są kolekcjonerami odznaczeń, nagród, orderów). Za drzwiami wejściowymi jego domu stoją walonki - ciepłe, filcowe obuwie chroniące przed mrozem. W wolnych chwilach Niedźwiedź parzy sobie herbatę z samowara i delektuje się jej smakiem, pijąc napój z pięknej porcelanowej filiżanki. W ten sposób w filmie wskrzesza się stereotyp tradycyjnego picia herbaty (чаепитие) i eksponuje samowar (jeden z głównych symboli Rosji). W bajce powielone są też stereotypy ulubionych form spędzania czasu wolnego przez Rosjan. Miś uwielbia grę w szachy (Rosja może poszczycić się wieloma arcymistrzami w tej dyscyplinie), hokej (odwołanie do licznych sukcesów reprezentacji, przede wszystkim ZSRR), wędkowanie. Warto zaznaczyć, że te same zainteresowania uczniowie poznają na początkowym etapie nauki języka rosyjskiego. Prawie zawsze, przy temacie hobby, w podręcznikach wymienia się: играть в шахматы (grać w szachy), играть в хоккей (grać w hokeja), ходить на рыбалку (chodzić na ryby), отдыхать на даче (odpoczywać na daczy) itd. Strój Maszy również nawiązuje do stereotypowych wyobrażeń cudzoziemców o Rosjanach. Dziewczynka ubrana jest w tradycyjną ludową sukienkę (sarafan), a na głowie ma zawiązaną chustkę. W jednym z odcinków biega w wojskowej czapce z motywem czerwonej gwiazdy, a w czołówce serialu pojawia się w kokoszniku - ludowym nakryciu głowy - i gra na bałałajce - instrumencie ludowym. W bajce uwagę zwracają też gesty Rosjan, odmienne od innych nacji.

${ }^{7}$ Zob. E. Chromiec, Dziecko wobec obcości kulturowej, Gdańsk: Gdańskie Wydawnictwo Psychologiczne 2004. 
W odcinku Przyszła wiosna (ros. Весна пришла) Masza po zjedzeniu pysznych cukierków oblizuje palce i robi to, jak każdy Rosjanin, zaczynając od kciuka. W wykonaniu np. Polaków ten gest wygląda zupełnie inaczej.

W kontekście omawianego serialu warto wspomnieć o metastereotypach, czyli przekonaniach własnej grupy na temat tego, w jaki sposób jest ona charakteryzowana przez innych. Autorzy animacji Masza i Niedźwiedź zachowują dystans do swojej nacji i są świadomi tego, jak ich widzą obcokrajowcy. Nie rezygnują z utartych stereotypów rosyjskości: samowara, który jest dziś w Rosji już tylko symbolem i pamiątką, niedźwiedzia, kokosznika, walonek, czapki z czerwoną gwiazdą, bałałajki itd. Autorzy animacji są świadomi funkcjonującego obrazu Rosji i Rosjan i utrwalają go „odgrywając” dobrze znane obrazy. Twórcy bajki nie boją się negatywnych i utartych stereotypów. Próbują jednak ,przemycić” i inne wyobrażenie o swoim kraju i jego mieszkańcach. Pokazują Rosjan czytających książki (Miś dużo czyta), doskonalących swoje umiejętności (Miś nieustannie zgłębia wiedzę na temat gry w szachy), interesujących się światowym kinem (w odcinku $B$ кино pojawiają się kadry ze światowych hitów filmowych, np. Titanica, King Konga).

W odcinku Pierwsza klasa (ros. Первый раз в первый класс) autorzy nawiązują do tradycji świętowania początku roku szkolnego - wydarzenia w Rosji szczególnie ważnego dla pierwszoklasistów i ich rodziców. Święto to nazywane jest również „Dniem wiedzy” (ros. День знаний) lub „świętem pierwszego dzwonka". Z tej okazji dzieci wręczają nauczycielom kwiaty (polskie dzieci zwyczajowo obdarowują nauczycieli kwiatami z okazji końca roku szkolnego).

W odcinku Ida święta (ros. Раз, два, три! Ёлочка, гори!) poznajemy tradycje związane z Nowym Rokiem - największym i najważniejszym świętem w Rosji. Autorzy bajki podkreślają m.in. tradycję wręczania sobie nawzajem kartek z życzeniami. Rosyjski tytuł Раз, два, три! Ёлочка, гори! nawiązuje do zwyczaju zapalania świeczek na choince noworocznej. $Z$ tej okazji śpiewa się też popularną wśród Rosjan piosenkę:

$$
\begin{aligned}
& \text { Раз, два, три - ёлочка, гори! } \\
& \text { Раз, два, три - праздник нам дари! } \\
& \text { Раз, два, три - ёлочка, гори! } \\
& \text { Раз, два, три - праздник нам дари! }
\end{aligned}
$$

Przytoczone przykłady to tylko niektóre elementy „rosyjskości” wyekscerpowane z odcinków serialu Masza i Niedźwiedź. Praca na oryginalnym materiale, jakim jest omawiana animacja, daje dzieciom możliwość kontaktu z językiem rosyjskim, daje im szanse nabycia pozytywnych doświadczeń i rozwinięcia motywacji do nauki tego języka. 
Z doświadczeń autorki wynika, że dzieci polskojęzyczne mogą oglądać bajkę w oryginale. Masza mówi bardzo niewiele, jej przyjaciel Niedźwiedź nie mówi w ogóle, porozumiewa się z dziewczynką rycząc, używając gestów, mimiki. Jak słusznie zauważają metodycy, dzieci w wieku przedszkolnym oraz wczesnoprzedszkolnym, na początku przygody z językiem obcym głównie słuchają i naśladują swoje otoczenie. Podobnie sytuacja wygląda przy przyswajaniu języka ojczystego. Mówienie jest poprzedzone długim okresem, w którym dziecko słucha, następnie zaczyna rozumieć i reagować przez wykonywanie czynności. Iwona Rybak zaznacza, że tematy na które rozmawiają przedszkolaki ograniczają się do podstawowych potrzeb i do zabaw. Sytuacje, w których uczestniczą, są przewidywalne i powtarzalne, a język, którego potrzebują, najczęściej odnosi się do przedmiotów i osób z ich otoczenia, które można po prostu wskazać ${ }^{8}$. Podobnie wygląada komunikacja Maszy z jej przyjaciółmi z lasu: Masza mówi krótkimi zdaniami, często powtarza słowa, parafrazuje, gestykuluje, odnosi się do przedmiotów z najbliższego otoczenia. Bajkę można oglądać w oryginale właśnie dzięki temu zabiegowi - redukcji dialogów do minimum. Dzieci bez problemów wydobywają znaczenia z kontekstu, interpretują ton głosu, gesty, sytuację i nie przywiązują wagi do niezrozumiałych słów.

$\mathrm{W}$ procesie kształcenia dzieci nieocenioną rolę odgrywa prowadzący zajęcia. Jerzy Brzeziński podkreśla, że to osobowość nauczyciela jest najważniejszym czynnikiem w organizacji nauczania dzieci ${ }^{9}$. Nauczyciel powinien stworzyć właściwą atmosferę i warunki do nauki oraz zabawy. Okoliczności, w jakich uczą się dzieci, są równie ważne jak sama znajomość języka. Na warsztatach „Zrozumieć Maszę" o dobrą atmosferę dbamy szczególnie. Spotkanie z dziećmi poprzedzone jest wysłaniem im zaproszenia: kolorowego, z wizerunkiem ich ulubionych bohaterów. Dzięki temu zabiegowi wzbudzamy w przedszkolakach ciekawość i przez to chętnie przychodzą na zajęcia. Sala, w której odbywają się warsztaty, jest również odpowiednio przygotowana. Najczęściej jest udekorowana plakatami, przedmiotami kojarzonymi z rosyjskością. Można powiesić flagę Rosji, białe, niebieskie i czerwone balony (zapoznajemy dzieci z układem kolorów na fladze rosyjskiej), mapę Rosji (zaznajamiamy dzieci z położeniem kraju, jego stolicą), rozstawić pamiątki przywożone z Rosji, np. uwielbiane przez najmłodszych matrioszki.

Podczas spotkania dzieci oglądają jeden odcinek serialu, następnie wykonują zadania związane z obejrzanym fragmentem. Mogą to być pytania o bohaterów,

\footnotetext{
${ }^{8}$ I. RYBAK, Jak dzieci ucza się języków obcych - mity i fakty, „Bliżej przedszkola” 168(2015), nr 9, s. 10-12.

9 J. Brzeziński, Nauczanie języków obcych dzieci, Warszawa: Wydawnictwa Szkolne i Pedagogiczne 1987, s. 166.
} 
przedmioty, sytuacje. Pytania są krótkie i wymagają krótkiej odpowiedzi. Dbamy o to, by proponowane ćwiczenia sprzyjały interakcji językowej. Dzieci powtarzają słowa za prowadzącą, odpowiadają na pytania przy pomocy słów: да (tak), нет (nie). Każdą podjętą próbę powtórzenia słów chwalimy i nagradzamy (naklejkami). Na spotkaniach warsztatowych dzieci uczą się wierszyków lub ich fragmentów. Wybierając utwory warto wybrać te, w których powtarzają się słowa podobne do polskich, np. лето (lato), зима (zima), снег (śnieg), солнце (słońce), горка (górka). Zaproponować można m.in. wiersz:

Как на горке - снег, снег,

И под горкой - снег, снег,

И на елке - снег, снег,

И под елкой - снег, снег,

А под снегом спит медведь.

Тише, мише - не шуметь ${ }^{10}$.

Spotkania zawsze mają formę warsztatów. Dzieci wiedzą o tym i same upominają się o zajęcia manualne. Najczęściej kolorują obrazki, układają specjalnie przygotowane puzzle (z motywem samowara, bałałajki, czapki uszanki, kokosznika). Przedszkolaki wykonują również kartki okolicznościowe, zapoznają się z literami współczesnego alfabetu rosyjskiego, z radością odtwarzają wybrane znaki. Ćwiczenia na spotkaniach dobierane są tak, by angażowały wszystkie zmysły.

Joanna Rokita-Jaśkow podkreśla, że nie ma sekretnego składnika i magicznej metody nauczania dzieci. Jednak na pewno należy kształtować u nich motywację, ponieważ to ona pozwala osiągnąć sukces w nauce ${ }^{11}$. Znana i lubiana bajka, jaką jest Masza i Niedźwiedź, podtrzymuje zainteresowanie dzieci i jest doskonałym elementem motywującym i aktywizującym, który może być wykorzystany również w warunkach przedszkolnych czy szkolnych. Na warsztatach „Zrozumieć Maszę" dzieci mają możliwość spotkania z kulturą i językiem rosyjskim. Realizowany projekt wdraża założenia edukacji międzykulturowej. Jak wiadomo w interkulturowym ukierunkowaniu dydaktyki języków obcych szczególna rola przypada przekazowi treści związanych z szeroko pojętą kulturą i realiami krajów, w których używa się danego języka obcego ${ }^{12}$. Na warsztatach dzieci nie tylko

${ }^{10}$ И. ТокмаковА, Медведь, dostęp online http://allforchildren.ru/poetry/animals294.php (10.09.2018).

${ }^{11}$ J. RoKITA-JAŚKOW, Spór o metodę, czyli jak najlepiej uczyć dzieci języków obcych, http://jows.pl/ content/spor-o-metode-czyli-jak-najlepiej-uczyc-dzieci-jezykow-obcych?page=2 (dostęp: 03.01.2019).

${ }^{12} \mathrm{P}$. Iwan, Zastosowanie multimediów do prezentacji wybranych aspektów realioznawstwa i kulturoznawstwa niemieckiego obszaru językowego, http://www.spnjo.pol.sl.pl/konferencja/ 
zapoznają się z brzmieniem języka rosyjskiego, jego melodyjnością, intonacją (oglądając bajkę w oryginale), ale też z kulturą, obyczajami i tradycjami Rosjan. Przedszkolaki porównują kulturę rosyjską z własną, to uczy je tolerancji oraz kształtuje wyobrażenie o różnicach kulturowych. Zaproponowane dzieciom zadania nie tylko sprzyjają ćwiczeniu pamięci i wyobraźni, ale też wzbudzają w nich ciekawość świata oraz przygotowują do komunikacji międzykulturowej. Podkreślić należy, że wiek przedszkolny uznawany jest przez pedagogów za najlepszy okres do rozpoczęcia edukacji międzykulturowej ${ }^{13}$.

Głównym celem projektu ,Zrozumieć Maszę” jest zainteresowanie i pozytywne nastawienie dzieci do języka rosyjskiego, wzbudzenie motywacji do poznawania kultury rosyjskiej. Wieloletnia już praktyka dowodzi, że cel ten jest osiągany. Dzieci wychodzą ze spotkań wesołe, podśpiewują piosenki, umieją pożegnać się w języku rosyjskim. Bardzo często przedszkola biorące udział w naszych warsztatach organizują, już we własnym zakresie, dzień bądź tydzień kultury rosyjskiej w swoich placówkach. Kontynuują w ten sposób swoją znajomość z Rosją i z jej, szeroko rozumianą, kulturą.

Reasumując, serial Masza i Niedźwiedź jest idealnym materiałem, który można wykorzystać do popularyzacji języka i kultury rosyjskiej wśród dzieci.

\section{BIBLIOGRAFIA}

BARTMIŃski J., Stereotypy mieszkaja w języku. Studia etnolingwistyczne, Lublin: Wydawnictwo UMCS 2007.

BRzEzIŃSKi J., Nauczanie języków obcych dzieci, Warszawa: Wydawnictwa Szkolne i Pedagogiczne 1987.

Chromiec E., Dziecko wobec obcości kulturowej, Gdańsk: Gdańskie Wydawnictwo Psychologiczne 2004.

IwAN P., Zastosowanie multimediów do prezentacji wybranych aspektów realioznawstwa $i$ kulturoznawstwa niemieckiego obszaru językowego, http://www.spnjo.pol.sl.pl/konferencja/ materiały/referaty/iwan.pdf (dostęp: 25.05.2017).

KĘPIŃSKi A., Lach i Moskal. Z dziejów stereotypu, Warszawa-Kraków: Państwowe Wydawnictwo Naukowe 1990.

Olechno-Wasiluk J., Из опыта приобщения к русскому языку и культуре польских дошкольников, „Вестник ТГПУ” 2016, No 3, s. 93-96 [Olechno-Wasiluk J., Iz opyta priobshcheniya k russkomu yazyku i kul'ture pol'skikh doshkol'nikov, „Vestnik TGPU” 2016, No 3, s. 93-96].

materiały/referaty/iwan.pdf (dostęp: 25.05.2013).

${ }^{13}$ Е.Ю. Протасова, Н.М. РодинА, З.А. Проскурина, З.А. БулАТовА, Педагогика мультикультурности для дошкольного возраста, «Иностранные языки в высшей школе» 2009, № 4, s. 23-33. 
RYвак I., Jak dzieci uczą się języków obcych - mity i fakty, „Bliżej Przedszkola” 168(2015), nr 9, s. 10-12.

Токмакова И., Медведь [Tokmakova I., Medved'], http://allforchildren.ru/poetry/animals294. php] (dostęp: 10.09.2018).

Протасова Е.Ю., РодИНА Н.М., ПроскУРИНА З.А., БуЛАТовА Е.А., Педагогика мультикультурности для дошкольного возраста, «Иностранные языки в высшей школе» 2009, № 4, s. 23-33 [Pro Tasova Ye.Yu., Rodina N. M., Proskurina Z. A., Bulatova Ye.A., Pedagogika mul'tikul'turn, «Inostrannyye yazyki v vysshey shkole» 2009, No 4, s. 23-33].

Rокіта-JAśKоw J., Spór o metodę, czyli jak najlepiej uczyć dzieci języków obcych, http://jows.pl/content/spor-o-metode-czyli-jak-najlepiej-uczyc-dzieci-jezykow-obcych?page=2 (dostęp: 03.01.2019).

\section{POPULARYZACJA JĘZYKA I KULTURY ROSYJSKIEJ WŚRÓD DZIECI. FENOMEN SERIALU ANIMOWANEGO MASZA I NIEDŹWIEDŹ}

\section{Streszczenie}

W niniejszym artykule autorka koncentruje się na możliwościach wykorzystania serialu animowanego Masza i Niedźwiedź w nauczaniu języka rosyjskiego dzieci w wieku przedszkolnym i wczesnoszkolnym. Zwraca uwagę na bogactwo elementów kultury rosyjskiej zawartych w serialu i przekazywanych widzowi ,przy okazji” narracji. Autorka dokonuje analizy stereotypów ulokowanych w animacji, szczególnie tych o treści poznawczej, tj. związanych z dniem powszednim Rosjan, ich zainteresowaniami, tradycjami, ubiorem. Publikacja niniejsza oparta jest na doświadczeniach autorki z realizacji własnego projektu pod hasłem: „Zrozumieć Maszę. Wesoło, kolorowo i ciekawie o języku i kulturze Rosji”. Zakłada on popularyzację języka i kultury rosyjskiej wśród dzieci oraz przygotowanie ich do uczestnictwa w dialogu międzykulturowym.

Słowa kluczowe: nauczanie dzieci; język rosyjski jako obcy; bajka multimedialna; dialog międzykulturowy; stereotypy.

\section{THE POPULARIZATION OF RUSSIAN LANGUAGE AND CULTURE AMONG CHILDREN. THE PHENOMENON OF THE ANIMATED FILM MASHA AND THE BEAR}

\section{Summary}

The paper focuses on the opportunities offered by a Russian animation series entitled Masha and the Bear when it comes to teaching Russian to kindergarten and early school-age children. The author believes that it is worth paying attention to the variety of cultural elements in the series and the way they are "accidentally" passed onto the recipient in the narrative. The author also analyses stereotypes employed in the animation, especially the cognitive ones, that is the ones related to everyday life of the Russians, their interests, traditions and clothing. The paper is based on the experience of the author, who carried out a project "Understanding Masha. Jolly, colourful and interesting presentation of the Russian culture and language." The aim of the project was to promote the language and culture of Russia among children, as well as preparing them to participating in intercultural dialogue.

Key words: teaching children; Russian language; multi-medial fairy tale; intercultural dialogue; stereotypes. 